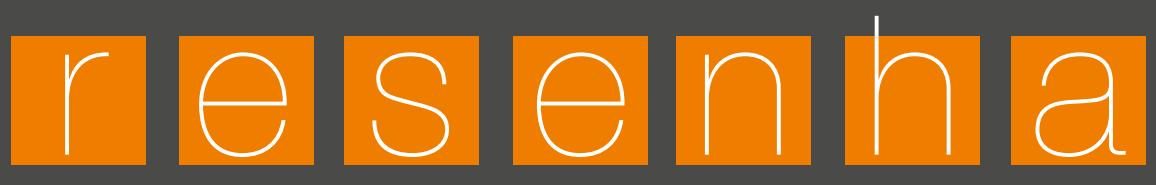


AÇÃO MIDIÁTICA, n. 10. Ju/Dez. 2015. Curitiba. PPGCOM-UFPR. ISSN 2238-0701 


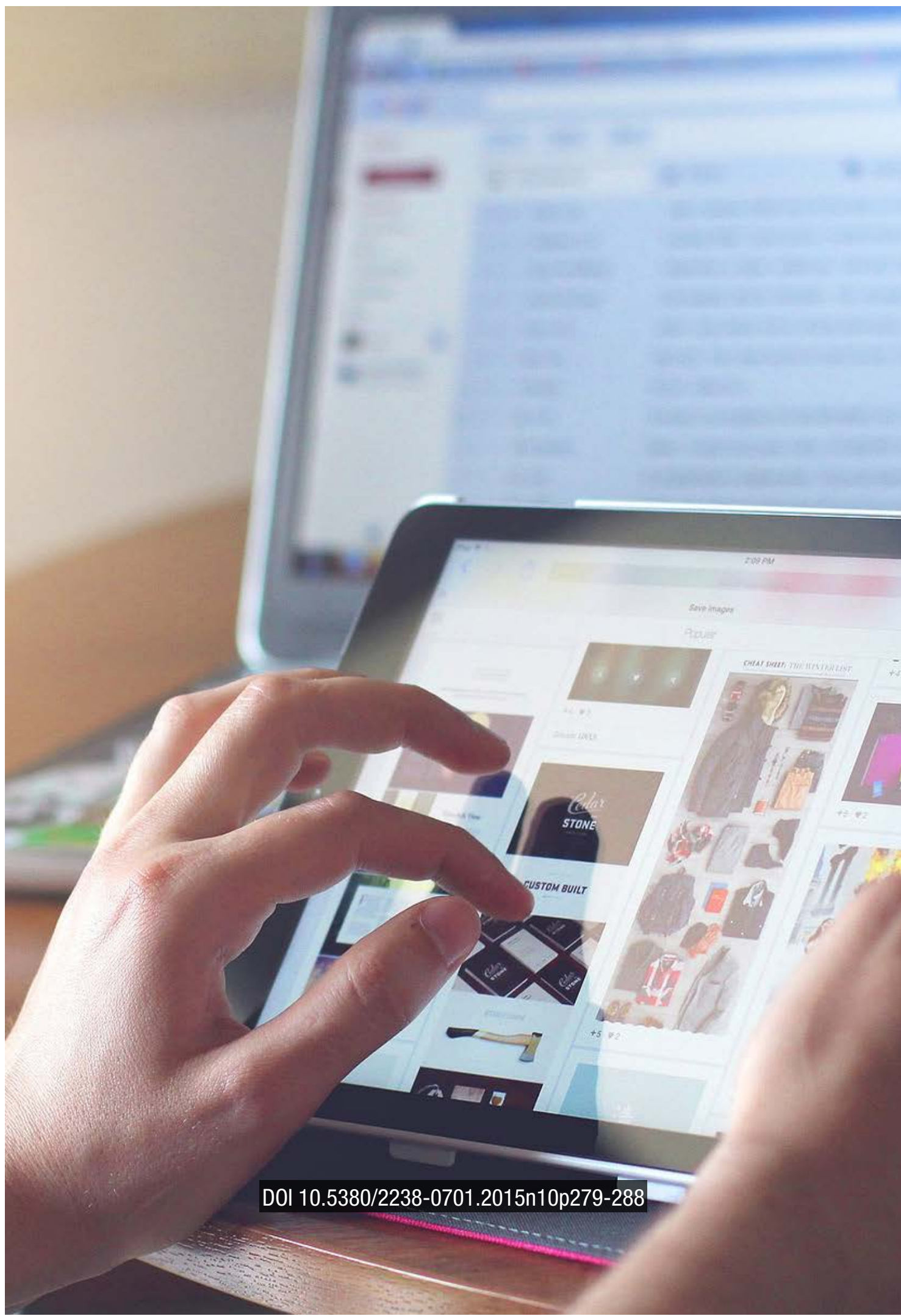


AÇÃO MIDIÁTICA, n. 10. Jul/Dez. 2015. Curitiba. PPGCOM-UFPR. ISSN 2238-0701 


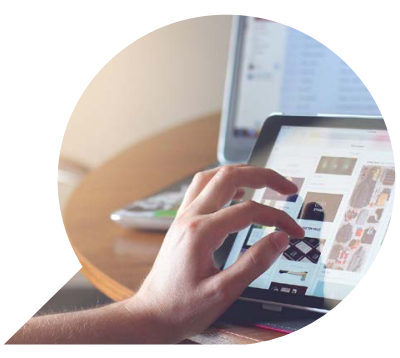

\section{Introdução às Teorias das Mídias Digitais e a busca inicial por uma reflexão epistemológica}

Introduction to the Theories of Digital Media and the initial search for an epistemological thought

Introducción a las Teorías de los Medios Digitales and la búsqueda inicial por una reflexión epistemológica

MANOELLA FORTES FIEBIG *

MARTINO, Luís Mauro Sá. Teoria das Mídias Digitais: Linguagens, ambientes e redes. - Petrópolis, RJ : Vozes, 2014. 291 páginas.

\footnotetext{
* Mestranda do Programa de Pós-Graduação em Comunicação da Universidade Federal do Paraná, bolsista CAPES e integrante do Grupo de Pesquisa Click Comunicação e Cultura Ciber.
} 
A partir da segunda metade do século XX e, em especial, desde a popularização ${ }^{1}$ da internet, nos anos 1990, inúmeros pesquisadores, provenientes das mais diferentes áreas do conhecimento se dedicaram a estudar as novas formas de comunicabilidade e sensibilidades evidenciadas com o surgimento de novas mídias e, principalmente, suas interferências no cotidiano das pessoas. Como consequência desse interesse acerca das mídias digitais e suas implicações no ambiente social, uma série de teorias foram sendo elaboradas, algumas com interfaces teóricas semelhantes, outras com tendências teóricas divergentes, que tensionaram o campo.

O livro “Teoria das Mídias Digitais: linguagens, ambientes e redes", resultado de cerca de seis anos de estudos, do pesquisador brasileiro Luís Mauro Sá Martino, doutor em Ciências Sociais pela PUC-SP, apresenta uma compilação destas teorias emergentes, em especial aquelas que ganharam maior notoriedade no âmbito científico, a fim de subsidiar as publicações que tomavam como tema central a sociedade e as mídias digitais. Já na contracapa do livro, o autor anuncia que a obra não diz respeito a tecnologias, máquinas ou aplicativos - ela se debruça sobre as relações entre seres humanos conectados; e conclui dizendo que o livro discorre "também sobre o modo como as pessoas entendem a si mesmas, seus relacionamentos, seus problemas e limitações".

Durante todo o percurso de leitura, o autor ressalta a face humana relacionada às tecnologias por meio de inferências acerca de seus usos no interior da sociedade. Na introdução, Martino esclarece seu propósito ao compor a obra: "o objetivo do livro é apresentar algumas das principais teorias das mídias digitais, resultado do trabalho de pesquisadores que, desde meados do século XX começaram a construir ideias, conceitos e pontos de vista que resultaram no estudo das mídias" (p.14).

Ao adotar uma abordagem de caráter expositivo, Martino vai apresentando as teorias e seus conceitos, sem fazer críticas mais enfáticas ou realizar discussões. Este é um posicionamento marcante nas páginas do livro, pois o autor investe na exposição fiel das principais características das diversas teorias, não fazendo uso de citações de

$1 \mathrm{O}$ termo popularização, neste caso, refere-se ao uso da internet para fins pessoais, levando em consideração que a rede internacional de computadores já era utilizada para fins comerciais em empresas e corporações governamentais. 
outros autores, tampouco denotando críticas ou emitindo opiniões pessoais sobre a teoria apresentada. Após cada explanação, o autor indica leituras complementares para que o leitor possa compreender com maior profundidade os conceitos em questão.

Nas dez páginas da Introdução, o autor apresenta as motivações pessoais que resultaram na publicação do livro, em 2014. Discorre também sobre alguns conceitos fundamentais para entender o trabalho. "O que são mídias digitais?" é seu primeiro questionamento e, logo em seguida, ele explica que as mídias tradicionais, tal qual conhecemos no século passado, passaram do suporte físico (mídias analógicas, como a televisão, o cinema, o rádio, jornais e revistas), para um meio eletrônico (a internet, com envio e recebimento de dados - sequências numéricas ou de dígitos, resultando em softwares, sites, blogs, redes sociais digitais, etc). A estas mídias, que vão além das analógicas e utilizam o virtual (que é real, pois suscita ações e sensações em seus receptores, porém perdem sua territorialidade, temporalidade e materialidade) como suporte, podemos denominar como mídias digitais.

Além disso, o autor já introduz alguns conceitos-chave, essenciais para entender os estudos gerais sobre as mídias digitais e sistematiza o significado de alguns conceitos fundamentais da área: barreira digital, ciberespaço, convergência, cultura participatória, inteligência coletiva, interatividade, interface, segurança e vigilância, ubiquidade, velocidade e virtualidade. Tais conceitos são apresentados em uma tabela elaborada com base em leituras específicas realizadas por Martino, norteando as teorias das mídias digitais. O livro é dividido em nove capítulos: (I) Conceitos básicos; (II) Redes sociais; (III) Mídias digitais, espaço público e democracia; (IV) Ambientes: A vida concreta; (V) Cultura: As formas das mídias digitais; (VI) A Teoria do Meio: Dos meios às mensagens; (VII) Linguagens: $\mathrm{O}$ que as mídias digitais têm a dizer?; (VIII) Mediação e mediatização da sociedade; e (IX) A crítica das práticas, uma trilha de 3 mil anos. Segundo Martino, "os capítulos podem ser lidos de maneira independente" (p. 14), já que cada um deles se dedica a apresentar teorias sobre um mesmo tema específico.

Em subcapítulos, Martino sempre apresenta um autor ou obra que trata da temática norteadora do capítulo em que estão inseridos. Por exemplo, no primeiro capítulo, que expõe conceitos básicos sobre tecnologia e mídias digitais, o autor apresenta os termos 
cunhados por Pierre Lévy no subcapítulo 3, denominado "Cibercultura, tecnologia e inteligência: Pierre Lévy”. Nas páginas seguintes Martino fala sobre cibercultura, ciberespaço e inteligência coletiva de maneira sintética e objetiva, visando à explicação dos estudos feitos por Lévy desde os anos 1980 e que estão disponíveis nos livros: Inteligência Coletiva: por uma antropologia do ciberespaço (1994); O que é o virtual? (1998); e Cibercultura (1999). Após a explanação, Martino sugere leituras complementares que irão dar consistência aos conceitos apresentados.

Além de Lévy, no primeiro capítulo Martino traz Henry Jenkins (sobre a Teoria da Convergência), Michael Heim (sobre a filosofia do mundo virtual conectado), Howard Rheingold (sobre o conceito de comunidade virtual) e Pryan Nayar (sobre cibercultura e estudos culturais). Já o segundo capítulo aborda o entendimento de redes sociais, passando por seus conceitos antropológicos, até o advento das redes sociais digitais e novas formas de comunicabilidade, trazendo autores como J.A. Barnes, Paul Baran, Mark Granovetter, Sacks e Graves, Mercklé e Albert-Laszló Barabási.

O capítulo III fala sobre a democracia e o espaço público na internet. Martino resgata o conceito de esfera pública, cunhado pelo filósofo alemão Jürgen Habermas, para introduzir o debate entre os espaços de discussão acerca dos assuntos de interesse público e a "praça pública" representada pela internet. Neste ponto o autor também traz reflexões sobre a política da sociedade em rede, de Manuel Castells; de esferas públicas conectadas, de Peter Dahlgern e Yochai Benkler e conclui com os limites e territorialidades da esfera pública virtual, trazendo como referência Zizi Papacharissi.

Nos capítulos seguintes, IV e V, o autor fala, respectivamente, sobre os ambientes da vida conectada e a cultura das mídias digitais, apresentando as Teorias da Solidão Conectada e da Proximidade Eletrônica para explicar sobre a representação das individualidades no ambiente virtual e a relação entre as pessoas no ciberespaço, além de nos exemplificar como as novas culturas nascem e se manifestam neste espaço virtual. O autor traz ainda a discussão sobre a produção de blogs pessoais e games, como exemplos de narrativas conectadas, que envolvem diversos atores sociais em uma rede de trocas simbólicas.

A “Teoria do Meio" é a temática norteadora do capítulo seis, com os estudos de Harold Inns, McLuhan, Joshua Meyrowitz e Kerckhove. $\mathrm{O}$ capítulo seguinte, que aborda as linguagens nas mídias digi- 
tais, faz uma conexão com o anterior e estende as discussões sobre as linguagens e modelos de comunicação surgidos nos meios digitais. Os subcapítulos trazem, entre outros autores, Lev Manovich, que se dedicou a estudar as linguagens, potencialidades e peculiaridades da "nova mídia", com Martino explanando os conceitos apresentados por Manovich no livro “The Language of New Media”, de 2001, como transcodificação, automação, viariabilidade, representação numérica e modularidade como princípios da nova mídia emergente.

Prosseguindo na discussão de meios, no capítulo VIII, o autor introduz o conceito de mediação e mediatização da sociedade, recorrendo a autores como Hjarvard e Livingstone, que falam sobre a vida contemporânea permeada pelas mídias digitais. Já no último capítulo Martino encerra a trajetória do livro com autores que são mais críticos em relação às mídias digitais e que podem ser considerados como pesquisadores cibercriticistas como Dominique Wolton e Andrew Keen, este último com uma visão mais pessimista quanto às influências das mídias digitais no ambiente social.

Após analisar todos os capítulos, pode-se dizer que a obra consiste em uma espécie de glossário das teorias contemporâneas das mídias digitais, visto que é dividido por autores e suas obras, abordando cada tema separadamente. Por esta razão, a impressão que temos é que Martino utiliza vários olhares (ou lentes) para tratar de um mesmo tema: as mídias digitais.

Ademais, na sua conclusão, que denomina "conexões finais", o autor fala sobre como as mídias digitais permeiam a vida e o cotidiano humano contemporâneo, entendendo que a sociedade trabalha, se diverte e se relaciona no ciberespaço, local virtual onde o tempo e o espaço parecem ser inexistentes. Além disso, ele relembra o que outros pesquisadores já falaram sobre a interface humana da tecnologia, já que ela nasce na sociedade de acordo as aspirações e demandas dos próprios seres humanos. Martino ressalta, ainda, que a internet reforça as possibilidades de ativismo político e social, cria novas linguagens e formas de comunicação, novas sensibilidades e maneiras de entretenimento. Assim, ele finaliza suas "conexões" explicando que "as alterações na tecnologia pela ação humana não se separam de sua cultura, de sua história e das sociedades formadas", para ele, o que interessa é que "a relação não é de causa e efeito, mas dialética: tecnologias foram e são formadas pela cultura humana” (MARTINO, 2014, p. 271). 
Mesmo que o livro apresente uma contribuição teórica útil, em especial para sistematizar as diversas teorias e autores da área, podese perceber que a obra é superficial em suas abordagens e constitui-se basicamente como uma introdução às teorias apresentadas - o que o autor não nega, já na introdução. Em uma perspectiva mais otimista, parece ser uma obra de iniciação para estudantes de graduação, por exemplo. Isto, porém, não diminui sua importância para o meio acadêmico, já que obras que reúnem um grande número de pesquisadores são essenciais para auxiliar na organização sistematizada de um pensamento epistemológico do campo em abordagem. 